First Peoples Child \& Family Review

An Interdisciplinary Journal Honouring the Voices, Perspectives, and Knowledges of

First Peoples through Research, Critical Analyses, Stories, Standpoints and Media

Reviews

\title{
Historical Trauma, Race-based Trauma and Resilience of Indigenous Peoples: A Literature Review
}

\section{Elizabeth Fast and Delphine Collin-Vézina}

\section{Volume 5, Number 1, 2010}

URI: https://id.erudit.org/iderudit/1069069ar

DOI: https://doi.org/10.7202/1069069ar

See table of contents

Publisher(s)

First Nations Child and Family Caring Society of Canada

ISSN

1708-489X (print)

2293-6610 (digital)

Explore this journal

Cite this article

Fast, E. \& Collin-Vézina, D. (2010). Historical Trauma, Race-based Trauma and Resilience of Indigenous Peoples: A Literature Review. First Peoples Child \& Family Review, 5(1), 126-136. https://doi.org/10.7202/1069069ar
Article abstract

This literature review examines the various responses to trauma suffered by Indigenous peoples as a result of governmental policies geared towards assimilation. Both traumatic and resilient responses are demonstrated at the individual, family and community levels. Much of the research that has been done in the United States to develop theories around historical trauma and race-based traumatic stress may also be applied to Canada's First Nations due to similar histories of oppression and colonization. Overall, the research finds that self government and a connection to culture and spirituality result in better outcomes for Indigenous peoples.
This document is protected by copyright law. Use of the services of Érudit (including reproduction) is subject to its terms and conditions, which can be viewed online.

https://apropos.erudit.org/en/users/policy-on-use/ 


\title{
Historical Trauma, Race-based Trauma and Resilience of Indigenous Peoples: A literature review
}

\author{
Elizabeth Fast ${ }^{\mathrm{a}}$ and Delphine Collin-Vézina ${ }^{\mathrm{b}}$
}

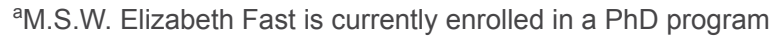
at the School of Social Work at McGill University. She is one of the coordinators for the 2008 Canadian Incidence Study of Reported Child Abuse and Neglect and works out of the Centre for Research on Children and Families at McGill University. Prior to returning to school, she worked for several years as a front-line child welfare practitioner. Her research interests include the overrepresentation of Aboriginal children in the child welfare system, the relationship between culture and resilience among Aboriginal people, youth justice issues and the evaluation of child sexual abuse in child welfare settings.

aph.D. Delphine Collin-Vézina is the Tier II Canadian Research Chair in Child Welfare and an assistant professor at the School of Social Work at McGill University. She is a clinical psychologist that has developed a strong interest in research and clinical topics related to social work, including child welfare and child maltreatment. Her research program aims at developing culturally-appropriate clues for designing early and effective therapeutic and preventative interventions for the diverse populations of traumatized people, one of which are First Nations children and youth. Dr. Collin-Vézina's research is informed by theoretical concepts in attachment and resiliency.
\end{abstract}

\section{Introduction}

The focus on negative outcomes facing Indigenous peoples may mask the diversity of responses to the challenges facing Aboriginal, First Nations and American Indian persons. Both resilient and negative outcomes for Indigenous persons are well documented but negative outcomes seem to get more attention in the media, which may contribute to both overt and more subtle forms of discrimination. This is for a

Questions or correspondence concerning this article may be addressed to:

elizabeth.fast@mcgill.ca

\section{Abstract}

This literature review examines the various responses to trauma suffered by Indigenous peoples as a result of governmental policies geared towards assimilation. Both traumatic and resilient responses are demonstrated at the individual, family and community levels. Much of the research that has been done in the United States to develop theories around historical trauma and race-based traumatic stress may also be applied to Canada's First Nations due to similar histories of oppression and colonization. Overall, the research finds that self-government and a connection to culture and spirituality result in better outcomes for Indigenous peoples.

number of reasons: the disparities between Indigenous and non-Indigenous peoples in countries like Canada, the U.S. and Australia when regarded as a whole are so striking that effective arguments for change in policy need to highlight these disparities to demonstrate the need for policy changes (Armitage, 1995; Cornell, 2006). As a consequence, the literature becomes fragmented between those who are trying to bring to light the devastating impacts of colonialism, and those that focus on resilient peoples, communities and Nations. This paper will seek to bridge the literature that attempts to explain the disparities between Indigenous and non-Indigenous peoples while taking into account the enormous cultural variation among tribes and Nations. Trauma models should be expanded and diversified to take into the historical and current day experiences of Indigenous peoples. Some types of trauma that can be applied to Indigenous peoples include intergenerational trauma, historical trauma and race-based trauma. Given the enormous challenges faced by many Indigenous cultures to survive, resilient responses to trauma are especially notable and take many forms. Resilience models that are found at the individual, family and community levels will be explored in more detail. 


\section{Disparities between Indigenous and non- Indigenous peoples}

The United Nation's Human development report found that if the Aboriginal population in Canada were taken out as a sub-group they would rank 48 th out of 174 countries for their level of overall development and 71 st for education, whereas the rest of Canada consistently ranks in top 5 (UN, 2006). Canada has been admonished by the United Nations Economic and Social Council who expressed serious concern over the significant disparities between Canada's First Nations and non-Aboriginals with regards to access to water, health, education and housing (UN, 2006). Almost 50\% of off-reserve Aboriginal children under the age of six live in low income families, compared to $18 \%$ of non-Aboriginal children and $57 \%$ of Aboriginal children that live in large urban centres are living in low-income families (Statistics Canada, 2008). When using the "community well-being index (CWB)" which takes into account education, income, housing and labor force participation, among the 'bottom 100 'Canadian communities, 92 are First Nations. Only one First Nation community ranks among the top 100 'Canadian communities in 2001. Inuit communities are typically distributed towards the middle of the CWB range (Beavon, 2006).

In addition to these more commonly used measures of well-being some sub-groups of Aboriginal peoples are inflicted with very high rates of suicide, drug and alcohol dependence and the resulting high rates of out-of-home placement of children (AFN, 2007; Kirmayer, 1994; Trocmé et al., 2005). The Regional Longitudinal Health Survey, in their sample of over 20,000 First Nations people from 10 regions across Canada found that over $15 \%$ of those surveyed had attempted suicide in their lifetime and 30\% had thought about suicide. Furthermore, $16 \%$ of the respondents consume five or more drinks of alcohol at least once a week (AFN, 2007). Although this paper cannot adequately cover the history of discriminatory policies targeted towards Aboriginal people by the Canadian government, a short summary below will help shed light on the differences between Aboriginal and nonAboriginal people described above and the resultant need for more research on both traumatic and resilient responses to these policies.

\section{Assimilation and the Canadian Government}

Before the arrival of European settlers, all of the First Nations governed themselves and had their own economic systems for ensuring that the needs of members of the nation were met (Duran \& Duran, 1995; Milloy, 1999). In some Nations, the potlatch ceremony allowed for families that had greater success in hunting, fishing or cultivation in a particular season to share with families that had less success. Although Nations differed one to the next, it was uncommon for tribes to claim specific pieces of land as their own. Instead, it was generally believed that land belonged to everyone and was not a possession to be claimed. European settlers with ambitions of making money off the land decided that they would claim it for themselves, despite International laws, which stated that the first people to find and inhabit land had ownership over it. The settlers used a clause in the law that allowed them to override this rule if the persons occupying the land were found to be too "savage" and thus forced many Nations to confine themselves to portions of land that the imperial government deemed suitable (Minister of Supply and Services Canada, 1996). These portions of land were often far removed from other populations and above the frost line making it difficult to grow food and establish businesses. The government wanted Nations to prove that they could be self-sufficient and contribute by "European standards" such as farming, industry and other business models of production, but this went against the way they had been supporting themselves since time immemorial and furthermore, most reserve lands were unsuited to agriculture or other economic enterprises. The Indian Act of 1876 and all of its amendments had as an explicit goal to control every facet of life on reserves and the agents that monitored Aboriginal peoples on reserves severely limited trading and other economic enterprises with neighboring Aboriginal and non-Aboriginal communities (Minister of Supply and Services Canada, 1996).

In order to further goals of making Aboriginal people follow European values, the Bagot Commission of 1842 and the Davin Report of 1879 were turning points in the history of residential schools. Both of these documents described a process whereby removing native children from their parents and schooling them outside of their communities would help the children to adapt to European values and Christian belief systems. The model was suggested based on schools that had already been opened in the U.S. for similar purposes. The Davin Report was based on observations of boarding schools in the U.S. and four that were already in operation in Ontario. The report made it clear that day schools were not adequate for assimilating children and that ongoing contact with their family members would only enable them to maintain their cultural values, beliefs and language - precisely what the government wanted to destroy (Minister of Supply and Services Canada, 1996). By 1890, dozens of schools, which were partnerships between the federal government and churches, were in full operation. Residential schooling thus became mandatory wherever it was available and school officials removed children from their homes if they did not come willingly (Milloy, 1999). The schools were chronically underfunded from the 
outset leading to unsanitary conditions, health epidemics, and hundreds of child deaths. Milloy (1999) recounts that in many instances, inspectors found raw sewage in sleeping and eating quarters of the children and that despite being reported to the authorities, little change occurred. Reports of inadequate standards of clothing and food were also common and demands by parents to return their children home to live in better conditions went unanswered. Underfunding also meant poorly trained and underpaid staff that used harsh physical discipline of children, often leading to physical abuse. Residential schools started to close down throughout the 1960s and 1970s although the last one in Saskatchewan did not close until 1984. Widespread sexual abuse came to public awareness in the late 1980s when adult survivors began coming forward (Milloy, 1999; Minister of Supply and Services Canada, 1996). Given the lack of parental role modeling and widespread physical and sexual abuse while attending residential schools, generations of survivors have likely lost the capacity to engage in nurturing social interaction with young children that promotes attachment and intimacy (Wesley- Esquimaux \& Smolewski, 2004).

The "sixties scoop" is a widely-used term that refers to a period of time when thousands of First Nations children were removed from their parents and placed them in nonAboriginal homes. Many scholars refer to this time period as a continuation of the residential school system because removal of Aboriginal children from their homes and communities continued, only under a different pretense. The justifications for removing children from their homes were largely due to cultural differences in parenting practices that were misunderstood as neglect by non-Aboriginal social workers or due to poor living conditions caused by governmental underfunding of housing and essential services on-reserve (Minister of Supply and Services Canada, 1996). Despite the gradual expansion of First Nations run child welfare organizations, the overrepresentation of Aboriginal children in out of home care continues to this day due to funding formulas dictated by the Indian and Northern Affairs Department that provide funding to child welfare organizations based on a head count of children in placement. This leaves little flexibility in the ability of organizations to provide prevention services that keep children and families together (Blackstock, Prakash, Loxley and Wien, 2005; Minister of Supply and Services Canada, 1996). Thus, Aboriginal children continue to be placed and adopted by nonAboriginal families, which, in turn, further disconnects them from their communities, languages, livelihoods and cultures (Ball, 2008). The 2003 Canadian Incidence Study of Reported Child Abuse and Neglect found that Aboriginal children continue to be reported to child welfare authorities more often, have their files substantiated and kept open more often, and are brought into care more often than non-Aboriginal children. The primary reason for intervention is what social workers call "neglect" and is often closely tied to poverty, addictions and structural issues such as poor housing conditions (MacLaurin, Trocmé, Fallon, Blackstock, Pitman, \& McCormack, 2008).

On March 31, 1998 the Canadian federal government provided a one-time grant of $\$ 350$ million dollars to the Aboriginal Healing Foundation, which was given an eleven-year mandate, ending March 31, 2009. According to their website, the Foundation was intended to encourage and support, through research and funding contributions, community-based Aboriginal directed healing initiatives which addressed the legacy of physical and sexual abuse suffered in Canada's Indian Residential School System, including intergenerational impacts. By admitting that widespread abuse and neglect occurred in the residential school systems, the government took one step in the direction of reconciliation, but by limiting the scope of the healing foundation to victims of physical and sexual abuse, it fails to take responsibility for the perverse nature of the schools in the first place. The impact of having attended residential school began the moment that the Davin Report's intent was to "take away the Indian in the child". Removing thousands of children from their caregivers, prohibiting cultural practices, cutting off children's hair and prohibiting contact between children and parents for long periods of time was in and of itself hugely traumatic (Brubaucher, 2006 \& Minister of Supply and Services Canada). The Foundation only recognizes children that were victims of overt physical or sexual abuse, but does not consider the emotional impact of denying children of their cultures and families as abuse. Furthermore, the residential schools settlement offers token amounts of money to any current survivor of a residential school, but not to family members of survivors if they are deceased, thereby failing to recognize any form of intergenerational trauma.

This is not to say that the children who were victims of abuse and neglect while in government care do not deserve special mention. In addition to the trauma inflicted on all children who were removed from their homes to attend residential schools, these experiences were greatly compounded by acts of child abuse and neglect. With the recognition of the widespread abuse that occurred, it is hopeful that the Canadian public will become more cognizant of the devastating impacts of colonialist policies that continue to this day.

Although these policies have irrefutably contributed to existing disparities between Indigenous and non-Indigenous peoples across the globe, Aboriginal scholars have cautioned against non-Aboriginal scholars attempting to find "linear causalities" between specific events or situations and poor outcomes for some Native people or communities (Fleming 
\& Ledogar, 2008). Instead, they assert the need for a more holistic and integrated understanding of what has led to these differences. Some scholars have drawn on literature from other cultural groups - such as studies on intergenerational trauma among Holocaust survivors - to explain the community level consequences of certain traumas (Brave Heart, 1998; Evans-Campbell, 2008). At a family level, widespread abuses suffered in residential schools most probably have led to intergenerational cycles of abuse and neglect that persist to this day (Evans-Campbell, 2008). In addition, daily assaults of racism and discrimination, referred to by some scholars as "microagressions" likely exacerbate the impact of other traumas (Carter, 2006; Whitbeck, Adams, Hoyt \& Chen, 2004). The following section will explore the need for a more holistic understanding of trauma and conclude with an examination of the many varieties of resilient responses to trauma.

\section{Trauma and Post Traumatic Stress Disorder}

Some groups of trauma researchers have called for both an expansion of what is considered trauma and for an alternative diagnostic or screening tool that does not label individuals as pathological or mentally ill (Brave Heart, 1998; Carter, 1999; Danieli, 1998). The DSM-IV-TR defines Post Traumatic Stress Disorder (PTSD) as "The person has been exposed to a traumatic event in which both of the following have been present: (1) The person experienced, witnessed, or was confronted with an event or events that involved actual or threatened death or serious injury, or a threat to the physical integrity of self or others (2) the person's response involved intense fear, helplessness, or horror" (APA, 2000). In order to expand this definition, alternative types of trauma have been put forward by researchers and communities including intergenerational trauma, historical trauma and race-based or insidious trauma (Brave Heart, 1998; Carter, 1999; Danieli, 1998). The common thread amongst these three theories is that historical factors interact with current day stressors and can result in either problematic or resilient outcomes in individuals, families and communities.

\section{Intergenerational trauma}

Most of the literature on intergenerational trauma refers to the work that has been done with the offspring of survivors of the Holocaust. The Holocaust has been seen as a relevant comparison to policies against Indigenous persons in Canada, the U.S. and Australia that were genocidal in intent and in effect (Brave Heart \& deBruyn, 1998). Grubich-Simitis (1984) worked with hundreds of descendants of Holocaust survivors and began to form a clinical impression that many suffered from "transposition" or acting out the uncompleted mourning processes of their parents, who had not been able to adequately mourn the many losses they suffered during the Holocaust. Some clients appeared to be simultaneously living in their own realities and in the fantasy life of one of their ancestors and feeling just as vulnerable to persecution as someone living during this time period. It is not difficult to see the parallel between these observations and specific historical moments for groups of Native peoples. Brave Heart \& deBruyn (1998) recall the Massacre at Wounded Knee in 1890 where hundreds were killed and their bodies were thrown into mass graves. In 1881, there was a governmental ban placed on traditional burials, spirit keeping and "wiping of the tears", therefore grief was compounded and became pathological resulting in elevated rates of suicide, whereby the living are "unconsciously motivated to join the deceased,"

Several studies have attempted to empirically demonstrate the intergenerational transmission of trauma, parenting deficits and other difficulties. Felsen \& Erlich (1990) in their study of 25 second generation holocaust survivors and 24 control subjects who were also Jewish but whose parents had no direct experience of the Holocaust found that there are certain character organization traits found with the descendants of survivors including a lower sense of selfworth and an unwanted identification with their mothers. The authors attribute the latter characteristic to the greater responsibility for meeting emotional needs that is generally attributed to the mother and the mother's difficulty in meeting the children's needs due to being overly critical of herself as a survivor (survivor's guilt). The subjects all indicated an overidentification with their mother and rated themselves as being self-critical, a highly undesirable identification by all subjects.

Bar-On, Eland, Kleber, Krell, Moore, Sagi, \& Soriano et al. (1998) criticize the underdevelopment of theories that explain the transmission of trauma from one generation. The authors assert that in contrast to clinical descriptions of second generation survivors, most empirical studies to date have failed to find significant differences between descendants of Holocaust survivors and control groups. They propose that a more fully developed theory will aid in understanding some of the more subtle findings between experimental and control groups and use attachment theory to guide their analyses in three studies based in Canada, Israel and the Netherlands. Several important factors disrupted the process of mourning in Holocaust survivors including time gaps in ascertaining the status of loved ones, the uncertainty of the exact time, date and location of death and the abandonment and betrayal experienced by children who lost parents. These children then grew up with a disrupted attachment and may have inadvertently passed this on to generations to come, treating children as adults that were capable of providing 
emotional comfort and support (Bowlby, 1951). The studies found what appeared to be disruptions in healthy attachments. In the Netherlands study, children of Holocaust victims $(\mathrm{n}=30)$ were more "parentified", or felt more responsibility for taking care of their parents than the control group $(\mathrm{n}=30)$ whose parents were Jewish but not war victims. In the Vancouver study, responses of 57 adult children of Holocaust survivors were analyzed and found that overall, children were preoccupied by their parent's sadness and tried to please them by only bringing home only good marks or avoiding asking questions about the Holocaust. Furthermore, these respondents did not feel entitled to happiness because their parents were not able to be happy. The Israeli case study of one man found that it was difficult for him to tell a coherent story that linked his past and their present because he felt obliged to move beyond the experiences of his parents as a symbol of the future, and yet were so wrapped up in the past because of untold secrets and memories that he always felt were present for his parents.

Once again, parallels between second-generation Holocaust survivors and the experiences of many Indigenous people are evident. Survivors of residential schools were often separated from their parents for years at a time. They likely felt abandoned by their parents and wondered why they did not come and take them away and save them from those that stole them from their communities. When these children became parents, they were likely preoccupied with memories of their traumatic pasts (of being abandoned or abused) and may have expected their children to provide them with the comfort and security that they did not get growing up in an institutionalized setting. Furthermore, this pattern of parenting will carry across several generations - until children have caregivers that have models of healthy and nurturing care, they will be forever robbed of breaking this cycle.

\section{Historical Trauma}

Brave Heart (1998) was the first to apply the concepts of intergeneration trauma to the Lakota people, naming it historical trauma. She relates that because the Lakota have an extended sense of "family", their grief is also expanded to include larger numbers of deceased. Traditional outward signs of grief included cutting one's hair and sometimes one's body, symbolizing the loss of the part of oneself. At the end of the mourning period, called "spirit keeping" (usually one year), the Lakota would "Release the spirit" and "wipe the tears" to resolve the grief and allow the mourned to come back and participate in society. Brave Heart (1998) argues that with the 1881 ban on traditional practices, Lakota grief was inhibited and compounded. She writes that "Lakota grief differs from the process described by Freud and Pollock - the degree of decathexis is different because the Lakota seek continued involvement with the spiritual world after the death of their loved ones, this makes them further predisposed to pathological grief because even partial decathexis (the ability to disengage from another spirit emotionally) is limited". In 1890, a massacre occurred against the Lakota people killing thousands in what is referred to as the "Wounded Knee Massacre". The bodies of the dead were thrown into mass graves and the survivors were left to deal with the aftermath without being permitted to grieve or bury the bodies in a way that allowed them to release the spirits. Brave Heart (1998) believes that this was the beginning of an overreliance on alcohol and elevated rates of suicide, which were ways of coping with unresolved feelings. She tested her hypotheses on 45 service providers during a four day psycho educational intervention which was designed to initiate the resolution of grief. She employed a pre and post test using the Lakota Grief experience questionnaire, self reports at the end of the intervention, and a follow up questionnaire after six weeks. The findings of the study included the following: 1. Education about historical trauma led to an increased awareness of the impact and associated grief of the traumatic Lakota history, 2. Sharing the effects with other Lakota people in a traditional context provided cathartic relief; and 3. Grief resolution was initiated for individuals, including a reduction in grief effects, a more positive identity and a commitment to individual and community healing. Differences between men and women were found suggesting that men were at an earlier stage of grief resolution (denial and trauma fixation) at the pre-test stage than women who were living with more guilt and shame. At the end of the intervention, women blamed themselves less and had lower grief scores, whereas men as a group felt more sadness, grief, anger, hopelessness, shame and guilt. However men's joy and pride simultaneously increased by 50\% (Brave Heart, 1999).

Denham (2008) uses the concept of historic trauma in his ethnographic fieldwork with a four-generation family living in Northern Idaho. His research consisted of seven formal interviews with the family "patriarch" and informal observations of family interactions. Denham contends that this family honors their ancestors by the passing of narratives from one generation to the next in a sharing fashion. The way that the past is framed, however, is where other families may differ one from the next. The "Coeur d'Alène" family reframes their narrative in a strengths-based approach which focuses on their assets despite the adversities they have endured. $\mathrm{He}$ writes that because trauma memories are different than other memories - in that they lack a cohesive plot - they are capable of shattering one's sense of self. This self then requires someone to help them make sense of what has happened to them so they are able to overcome resulting obstacles. By passing a resilient narrative from one generation to the next, this family helps future generations make sense of their past and gives them strength and knowledge to overcome discrimination and to 
educate others that are more ignorant than themselves. The author concludes that historic trauma needs to be separated from responses to trauma, which can be both pathological and resilient (Denham, 2008).

Abadian (2006) made a similar argument as Denham (2008) in her presentation at the "Healing our Spirits Worldwide" conference. She argues that cultural renewal can be as dangerous as it can be rehabilitative. She refers to the Lakota people's historical attempts to renew culture that ended tragically - as in the 1890 Massacre of Wounded Knee. Furthermore, other so-called cultural renewals, such as Hitler's attempts to renew the "great Aryan nation" or Serbia's attempt at cultural resurgence have all ended horribly and been toxic to survivors. Abadian argues that cultural renewal requires paying attention to the stories that one tells themselves in relationship to others and who is responsible for the way things currently are. She refers to these stories as meta-narratives and asserts that toxic cultural renewal is an outcome of toxic cultural narratives. In turn, these cultural narratives are the outcome of past traumas. The first step in the regeneration of healthy and affirming cultures is the telling of life-affirming and healthy narratives. She draws on the example of a young child who was sexually abused by an extended family member. Because the child only has "pre-operational thinking" (Piaget, 1928) or believes that everything that happens is as a direct result of what they have done, they come to believe that any harm that occurs is their fault. This child thus goes through his life believing he is damaged, unloveable and unworthy of healthy relationships. These "post-traumatic" narratives tend to be habitual, frozen in the past, self-referential and selfreinforcing. In the same way, entire communities can pass on unhealthy narratives to future generations. Healthy traditional communities were able to deal with trauma through the sweat lodge, rituals to support those left behind by loved ones and through the adoption of orphaned children as a regular practice. But when entire communities experience the same traumas for generations, the very mechanisms that helped them to cope become destroyed in the process. The whole group becomes frozen in time and the collective narratives become post-traumatic. Abadian points to religious doctrine as another example of toxic narratives that get past on through time and that label people as "better than" or "worse than" anyone else based on their commitment to religion. She calls these beliefs falsely empowering and argues that doctrines of Christianity, Judaism and Islam emerged from their own historical traumas and have carried these forward and traumatized millions of people worldwide into believing that any one person can be more important or worthy of God's love. Cultural renewal thus requires a cleansing of the elements of post-traumatic subcultures that no longer serve people and communities and keep them stuck in a traumatic past.

Evans-Campbell (2008) suggests that the concept of historical trauma could be applied to all colonized, Indigenous peoples. The author argues that the diagnoses such as Post Traumatic Stress Disorder do not address multi-generational traumas; as the focus is too individualized and does not take into account the social aspects of reactions to trauma, nor does it address the way that historical traumas may interact and compound currently experienced traumas such as intrafamilial abuse, suicide of family members and daily racism and discrimination. She suggests that the criteria for historical trauma should include the following: 1. Many people in the community experienced it, 2 . the events generated high levels of collective distress (demonstrated both empirically and narratively), and 3. The events were perpetuated by outsiders with a destructive intent - often a genocidal intent, making them particularly devastating. Instead of focusing on the individual impact of trauma, Evans-Campbell proposes a multi-level framework for understanding overlapping causes. She argues that trauma is best understood as impacting at three levels: the individual, the family and the community. At the individual level, trauma manifests itself in mental and physical health problems - PTSD, guilt, anxiety and depression. At the family level, symptoms may include impaired communication and stress around parenting (or attachment problems seen in children). The entire community may suffer from the breakdown of traditional culture and values, the loss of traditional rites of passage, high rates of alcoholism, physical illness (obesity) and internalized racism (Duran \& Duran, 1995).

Whitbeck, Adams, Hoyt \& Chen (2004) in conjunction with tribal elders from nine reserves in both Canada and the U.S. developed two scales: the Historical Loss Scale and the Historical Loss Associated Symptom Scale Latent construct in an attempt to empirically capture the impacts of historical trauma. The first scale consists of 12 items, each of which lists a type of loss identified by focus groups of elders. These include loss of: land, language, culture, spiritual ways, family and family ties, self-respect, trust, people through early death, children's loss of respect for elders and traditional ways. The Historical loss associated symptoms scale is also made of twelve items and specifies symptoms identified by focus group members and other participants. These include sadness, depression, anger, anxiety, nervousness, shame, loss of concentration, isolation or distance from other people, loss of sleep, rage, feeling uncomfortable around white people, fear or distrust of the intentions of white people, feeling as though it is happening again, feeling like avoiding places or people. Both items have 
high internal reliability, with Cronbach's alpha scores of 94 for historical loss and 90 for historical loss associated symptoms. In a subsequent study of 452 American Indian parents of children 10-12 years old almost three quarters of the sample met the criteria for lifetime alcohol abuse and of those, $15 \%$ met the criteria for 12 month alcohol abuse. Historical loss mediated the effects of perceived discrimination, suggesting that historical loss and the resolution of these losses have impacts on alcohol abuse. The authors caution that this is exploratory work done only with one Nation, but that the scales may be adapted to reflect the losses and symptoms of other groups as well (Whitbeck, Hoyt, Chen \& Adams, 2004).

Clinicians that work with Indigenous peoples around manifestations of trauma should also be aware of culturally appropriate treatment models. Duran \& Duran (1995) argue for a shift in the counselor's worldview when working Indigenous populations. The authors relate that based on their experience working with several different tribes in the U.S., most Indigenous peoples' belief systems about mental health and healing are very different from euro-centric viewpoints. For example, the concept of time is generally used by western mental health counselors to set goals for treatment. For Indigenous peoples, it may not be a length of time that is required to heal, but rather the intensity in which they engage in the process. Dancing intensely during a traditional ceremony may provide as much cathartic relief as discussing problems over a longer period of time. Furthermore, western notions of well-being such as employment, income levels and ownership of property are not necessarily applicable to standards that Native peoples aspire to. Traditionally, capitalist models were not part of Native culture and instead ceremonies to share wealth among members of tribes or clans were an important way of creating balance and harmony in communities. Standard notions of functioning and well-being should be continually questioned and modified depending on what goals the person has for themselves (Duran \& Duran, 1995).

Although the transmission of trauma from one generation to the next may explain some of the current mental health problems and other disparities between Aboriginal and non-Aboriginal people, it is likely only one piece of the story. There are several other compounding factors that need to be examined in order to begin to have a holistic understanding of disparities.

\section{Race-Based Trauma and discrimination}

Carter (2007) in his major contribution article proposes that race-based traumatic stress injury be recognized as an "emotional or physical pain or the threat of emotional or physical pain stemming from racism in the form of harassment, discrimination or discriminatory harassment (aversive hostility)". Racial encounters can be interpersonal, institutional or through cultural racism. The trauma resulting from an event should be determined by the severity of the individual's reaction to the event (and the cluster of symptoms that accompanies it), because severity may be a consequence of the cumulative effects of racism throughout the person's life. The event that causes symptoms to manifest may be less serious than other events, but the additive factor causes the person to feel they cannot take anymore. Carter asserts that although race-related stress has been studied, trauma researchers do not generally consider racism in the diagnosis of PTSD. Carter also argues that discrimination can stem from historical policies and can infiltrate into current day myths and misconceptions about people of color or ethnic minorities. Histories of colonization and oppression cannot be separated out from everyday acts of racism and discrimination.

Bryant-Davis (2007) responds to and expands on Carter's argument for the recognition of race-based trauma. She argues that clinicians and those who work with the public need to be sensitized to the multiple and overlapping types of trauma that people experience in their lifetimes and should specifically assess ethnic minorities for instances of race-based trauma. The author feels that it is irresponsible to try and avoid issues of race and discrimination due to the counselor or psychologist feeling uncomfortable with the topic. She also writes that race-based trauma should not be pathologized, but that any kind of trauma will inevitably lead to victim blaming by a public that is not educated or sensitized. Therefore, it is not enough to keep race-based trauma separate from the DSM; work on educating the public needs to be done at multiple levels to support traumatized persons. There is some ambivalence in Bryant-Davis' argument because she nevertheless finds the work of trauma experts helpful in using the same cluster of symptoms when assessing race-based trauma as PTSD. She asserts that attention should be paid to reports of intrusive thoughts, hyperarousal, numbing, intense emotional reactions, difficulty concentrating, difficulty with memory, feelings of destructiveness towards self or others and psychosomatic reactions (Bryant-Davis, 2007; van der Kolk, McFarlane \& van der Hart, 1996).

A handful of researchers have attempted to measure the relationship of perceived discrimination with other mental health outcomes such as depression, suicide attempts and alcoholism among American Indians (Walls, 2007; Whitbeck, 2002 \& 2004). Whitbeck (2002) in concert with an advisory committee comprised of American Indian elders and tribe members from one nation developed an 11 item scale to measure how often respondents had been: insulted, treated disrespectfully, hassled by police, ignored, recipients of a 
racial slur, threatened with physical harm, suspected of doing something wrong, treated unfairly, expected not to do well by whites, discouraged to achieve an important goal and treated unfairly in courts as a consequence of their AI minority status. The response categories ranged from 1 (never) to 4 (always). The authors found that the scale has a high internal reliability (Cronbach's alpha of 0.90). The studies found that discrimination was correlated with higher alcohol use and suicide attempts and protective factors such as involvement in traditional activities disappeared when respondents had suffered from high levels of perceived discrimination. Thus, discrimination may lead to a broader range of symptoms than those officially recognized by a diagnosis of PTSD as BryantDavis (2007) suggests.

Both race-based trauma and historical trauma are only beginning to be recognized as legitimate frameworks by which to address mental health problems with Native peoples. Although Carter (2007) makes an important argument against pathologizing a trauma that is a result of society's ignorance, an official recognition of suffering by the American Psychiatric Association would go a long way towards sensitizing the thousands of clinicians that work with ethnic minorities and Indigenous peoples on a regular basis.

\section{Resilient Responses to Trauma \& Discrimination}

Fleming \& Ledogar (2008) provide a summary of resilience models and argue that although early models of resilience focused on the individual's ability to succeed despite adversity, there has been an ongoing search by researchers to find models that reflect resilience at not only the level of the individual, but also the family, community and cultural levels. Research completed on resilience in Indigenous communities has examined both individual factors that contribute to positive outcomes, and, more recently, community-level variables that may prove beneficial for large numbers of people within the community. Because the causes of many problems were widespread governmental policies and practices that affected whole nations of peoples, it is logical to study resilience at a community level - even if many of the problems have now spread to families and individuals

\section{Resilience as Self-government}

There is strong evidence to believe that Aboriginal quality of life would increase with greater expansion of self-governed nations. Chandler and Lalonde (1998 \& 2004) found that of 196 First Nations communities surveyed in British Colombia, 111 had not a single suicide. Self government was greatest protective factor against suicide and all markers of cultural continuity (land claims, education, health services, cultural facilities, police \& fire services, women in government and community run child welfare services) were associated with lower suicide rates. In communities that had only one or a few of these services, the rates of associated suicide were as great as six times that of the overall population.

Cornell (2006) as part of the Harvard University Economic Development project argues that Australia, New Zealand, Canada, and the United States have much in common - including the fact that all four are predominantly European-settler societies, English-speaking, have legal and political systems that share a primarily English heritage and also share a particular pattern of relationships with Indigenous peoples. In all four, European settlement often violently dispossessed Indigenous peoples, but Indigenous peoples remain today on remnant lands have all engaged to one degree or another in movements for Indigenous self-determination. Furthermore, Cornell (2006) asserts that the central governments have tended to be more willing to address issues of Indigenous poverty than issues of Indigenous self-determination. Overall disparities between Indigenous and non-Indigenous persons mask the fact that some Nations are outperforming not only other Indigenous communities, but also non-Indigenous communities. Tribes and Nations in the United States that have successfully implemented self government in one facet or another have seen reduced reliance on social assistance, reduced unemployment, the emergence of diverse and viable economic enterprises on reservation lands, more effective management of social services and programs (including language and cultural components) and improved management of natural resources (Jorgenson, 1997, 2000 \& Krepps, 1992). Cornell \& Kalt (2007) describe two approaches to economic stimulation in American Indian nations. The authors write that the standard approach that began in the 1920s has five main characteristics: "(1) decision making is short term and non-strategic; (2) persons or organizations other than the Native nation set the development agenda; (3) development is treated primarily as an economic problem; (4) Indigenous culture is viewed as an obstacle to development and (5) Elected leadership serves primarily as a distributor of resources". The approach doesn't always have all five of these elements but in general it has been wrought with corrupt leadership, an economy highly dependent on money from the federal government and ongoing poverty and an impression of incompetence that undermines future attempts to re-gain sovereignty of their nation. In contrast, the Nation-building approach sees Native nations make all the decisions, governing institutions adhere to Indigenous political culture and decision making is strategic and long-term. In many communities, governing institutions are the remnants of colonialism and the electoral system is based on the British 
model. When the authors refer to governance structures that adhere to Indigenous culture, they are referring to structures that have meaning and significance for that particular tribe or nation and therefore will inevitably be less prone to corruption and failure (Milloy, 1999). Examples of prosperous Nations in the U.S. are the Citizen Potawatomi in Oklahoma, the Mississipi Choctaw and the Salish and Kootenai. All three Nations built themselves up from minimal assets and reliance on federal money to being fully self-governed - in some cases with their own Supreme Court system - and with diversified economies consisting of banks, golf courses, casinos, farms and retail food chains. The Citizen Potawatomi Nation funnels their profits into services for citizens including health and wellness, early childhood development programs and an award-winning small business development program. Unemployment is virtually non-existent, the community members are healthier mentally, physically and culturally. Cornell and Kalt (2007) assert that these experiences are applicable to Indigenous peoples across all four countries, but also caution that self-determined Indigenous governance in these countries is likely to be diverse, and that a single form of self-governance is unlikely to work across groups or across countries.

\section{Resilience as Cultural and Spiritual Renewal}

A small number of researchers have begun to work with tribe members to develop tools that measure traditional spiritual commitments or cultural connection and the relationship to resiliency among Indigenous populations. Although there are distinct interpretations of these concepts that vary by tribe and culture, American Indians and the First Nations of Canada share a history of massacre, colonialism and high rates of out of home placement of children. Whitbeck, Adams, Hoyt \& Chen (2004) were the first to employ the term enculturation using three separate measurements: traditional spirituality, traditional activities and cultural identification. The Healing Pathways Project used these measures for their three year lagged sequential study on four American Indian and five First Nations reservations (Walls, Johnson, Whitbeck and Hoyt, 2006; Whitbeck, Chen, Hoyt \& Adams, 2004). In one set of analyses, 746 youth aged 10-12 were asked about suicidal thoughts and behaviors, discrimination, negative life events, alcohol use, depressive symptoms, delinquency, anger, self-esteem and enculturation. Enculturation and traditionality were negatively associated with suicidal behaviors, whereas discrimination and negative life events were positively associated with suicidal behaviors (Walls, 2007). This combination of three measurements appears promising for several reasons: it was developed in consultation with tribal members and elders, the measures contain many cultural components specific to both Native American and First Nations people and the traditional activities component, although not exhaustive, includes a large variety of traditional activities (19 in total) that span across cultures. In addition, the incorporation of elements that measure beliefs, actions and identification is a more holistic way of capturing cultural connection.

A cross-sectional survey of 1, 456 American Indian Tribal members aged $15-54$ years old used a cultural spiritual orientation scaled and found that those who were more culturally or spiritually oriented were half as likely to report a history of attempting suicide than those with a low score (Garroutte, 2003).

Anderson \& Ledogar (2008) provide a summary of 15 studies that have been completed in Canada that examine protective factors among youth across a wide range of issues including suicide prevention, tobacco use, risky sexual behavior, pre-natal health and domestic violence prevention. Some of the different constructs used to measure contribution to resiliency were: spirituality, sense of coherence, history of abuse, knowledge of consequences, pride in one's heritage, self-esteem, subjective norms, agency or self-efficacy, level of distress, involvement in traditional ways, church attendance, level of support, parental care, parental monitoring, parental attitudes, influence of peers and community influence. Associations were found between resilience and mastery, self-esteem, low levels of personal distress and pride in one's heritage. Although these were the only associations that were found to be significant, the authors assert that limitations, such as small sample sizes in many of the studies, may have contributed to the lack of association. Nevertheless, a common finding across these studies is that belief in traditional culture and values and participation in cultural practices provides some kind of a buffer against adversity and risk-taking. The very element that governmental policy sought out to destroy has turned out to be vital to the physical and emotional well-being of Indigenous peoples.

\section{Future Directions}

Research that has been done thus far clearly supports the theoretical frameworks of intergenerational, historical and race-based trauma. Furthermore, the notion of "culture", be it at an individual, family or community level is clearly a protective factor many Indigenous people. The developments in the theoretical literature on historical trauma as first described by Brave Heart (1998) are gaining some recognition, but more measures are needed to test the construct of historical trauma among a greater variety of cultural groups in order to confirm its applicability to different cultures. Whitbeck and colleagues 
First Peoples Child \& Family Review, Volume 5, Number 1, 2010

(2002 \& 2004) have begun to examine the interplay between a number of factors that both contribute to and undermine resiliency including perceived discrimination, enculturation, historical trauma, historical loss, alcohol use and suicidality.

What continues to be lacking is the ability to study resiliency of Aboriginal or Native American people living in urban and isolated rural areas. Like other cultural groups, enormous differences may be evident from one generation to the next and depending on whether someone has ever lived on a reserve community or not. Most of the studies examining the relationship between resiliency and community well-being are done with people living on-reserve. How can some of the positive findings from the studies cited above be translated into work with Aboriginal peoples living off-reserve? One area of future research may be to work with families that reside in communities or cities with a greater access to cultural resources (such as urban Native friendship centres) or with ongoing connections to friends or family members living on reserve to see how their level of involvement with such resources serves as a protective factor against the increased stressors of living in a city including discrimination, negative stereotyping and greater levels of financial stress.

No scale or measure can be thought to measure the countless losses suffered by Aboriginal peoples in Canada and Indigenous peoples across the globe. The one time grant of $\$ 350$ million to be spread over 11 years from the Canadian federal government is a first step in addressing the multiple losses endured by Aboriginal peoples. However, this money, without any kind of permanent structure or ongoing funding will not likely scratch the surface of the multiple and competing needs of generations of Aboriginal peoples affected by institutional racism and discrimination. Furthermore, only the measurable act of attendance in residential schools is being compensated. The loss of lands, gender roles, traditional family patterns and governance structures (to name only a few of the losses) are in no way being recognized as contributing to the suffering that continues for many Indigenous peoples. Although more Canadian research would further the argument, there appears to be no legitimate reason against further stalling by the government to settle land claims and reestablish the inherent right of First Nations to self-govern. If this transition is done properly (i.e. First Nations led, respecting traditional governance structures, etc.) self-government would likely decrease disparities between Aboriginal and non-Aboriginal peoples, and result in healthier individuals, families and communities.

\section{References}

Abadian, S. (2006). Cultural healing: When cultural renewal is reparative and when it is toxic. Pimatisiwin: A Journal of Aboriginal and Indigenous Community Health, 4(2), 5-28. Available online at http://www. pimatisiwin.com/uploads/834803515.pdf.

American Psychiatric Association (2000). Diagnostic and Statistical Manual of Mental Disorder (4th ed, text rev.). Washington, D.C.: Author.

Andersson, N. \& Ledogar, R.J. (2008). The CIET Aboriginal youth resilience studies: 14 years of capacity building and methods development in Canada. Pimatisiwin: A Journal of Aboriginal and Indigenous Community Health, 6, 65-88. Available online at http://www.pimatisiwin.com/ uploads/1068348808.pdf.

Armitage, A. (1995). Comparing the Policy of Aboriginal Assimilation. Vancouver, B.C.: University of British Colombia Press.

Assembly of First Nations (2007). First Nations Regional Longitudinal Health Survey: Results for Adults, Youth and Children Living in First Nations Communities (RHS) (2002/2003) (pp. 1-322). Ottawa, ON: Author.

Ball, J. (2008). Promoting equity and dignity for Aboriginal children in Canada. Choices: Institute for Research on Public Policy, 14, 1-28.

Bar-On, D., Eland, J., Kleber, R., Krell, R., Moore, Y., Sagi, A., Soriano, E., et al. (1998). Multigenerational perspectives on coping with the Holocaust experience: An attachment perspective for understanding the developmental sequelae of trauma across generations. International Journal of Behavioral Development, 22, 315-338.

Beavon, D. C., M. (2003). An Application of the United Nations Human Development Index to Registered Indians in Canada, 1996. Vancouver: UBC Press.

Blackstock, C., Prakash, T., Loxley, J., \& Wien, F. (2007). Wen:de: We are Coming to the Light of Day (pp. 1-229). Ottawa, ON: First Nations Child and Family Caring Society. Available online at http://www.fncfcs. com/docs/WendeReport.pdf.

Bowlby, J. (1951). Maternal care and mental health. World Health Organization Monograph (Serial No. 2).

Brave Heart, Y. H. M. (1999). Gender Differences in the Historical Trauma Response Among the Lakota. Journal of Health and Social Policy, 10, 1-21.

Brave Heart, Y.H.M. (1998). The return to the sacred path: Healing the historical trauma and historical unresolved grief response among the Lakota through a psychoeducational group intervention. Smith College Studies in Social Work, 68, 280-305.

Brave Heart, Y. H. M. \&. Debruyn, L. (1998). The American Indian Holocaust: Healing historical unresolved grief. American Indian and Alaska Native Mental Health Research, 8, 56-78.

Brubaucher, M. (2006). Coming Home: The Story of Tikinagan Child and Family Services. Sioux Lookout, ON: Tikinagan Child and Family Services.

Bryant-Davis, T. (2007). Healing Requires Recognition: The case for racebased traumatic stress. The Counseling Psychologist, 35, 135-143.

Minister of Supply and Services Canada (1996). Royal Commission on Aboriginal Peoples. Report. Vol 1. Ottawa, ON: Author.

Carter, R. T. (2007). Racism and psychological and emotional Injury: Recognizing and assessing race-based traumatic stress. The Counseling Psychologist, 35, 13-105. 


\section{Historical Trauma, Race-based Trauma and Resilience of Indigenous Peoples}

Chandler, M., \& Lalonde, C. (1998). Cultural continuity as a hedge against suicide in Canada's First Nations. Transcultural Psychiatry, 35, 191-219.

Chandler, M., \& Lalonde, C. (2004). Transferring whose knowledge? Exchanging whose best practices?: On knowing about Indigenous knowledge and Aboriginal suicide. In J. White, P. Maxim, \& D. Beavon (Eds.), Aboriginal Policy Research: Setting the Agenda for Change, Vol. II. (pp. 111-123). Toronto: Thompson Educational Publishing.

Cornell, S. (2006). Indigenous peoples, poverty and self-determination in Australia, New Zealand, Canada and the United States. The Native Nations Institute for Leadership, Management and Policy, 39pp.

Cornell, S. \& Kalt., J. (2007). Two approaches to the development of Native nations: One works, the other doesn't. In M. Jorgensen (Ed.). Rebuilding Native Nations (pp. 3-33). Tuscon: The University of Arizona Press.

Danieli, Y. (1998). Integenerational handbook of mutilgenerational legacies of trauma. New York: Plenum.

Denham, A. (2008). Rethinking historical trauma: Narratives of resilience. Transcultural Psychiatry, 45, 391-414.

Duran, E. \& Duran, B. (1995). Native American Postcolonial Psychology. State University of New York Press, Albany.

Evans-Campbell, T. (2008). Historical trauma in American Indian/Native Alaska communities: A multi-level framework for exploring impacts on individuals, families and communities. Journal of Interpersonal Violence, 23, 316-38.

Felsen, I. \& Erlich, S. (1990). Identification patterns of offspring of Holocaust survivors with their parents. American Journal of Orthopsychiatry, 60, 506-520.

Fleming, J. \& Ledogar., R. (2008). Resilience, an evolving concept: A review of literature relevant to Aboriginal research. Pimatisiwin: A Journal of Aboriginal and Indigenous Community Health, 6, 7-23. Available online at http://www.pimatisiwin.com/online/?page id=221.

Fournier, S. \& Crey, E. (1997). Stolen from our embrace: The abduction of First Nations children and the restoration of Aboriginal communities. Toronto: Douglas \&MacIntyre.

Garroutte, E., Goldberg, J., Beals, J., Herell, R., Manson, S. \& the AISUPERPFP team (2003). Spirituality and attempted suicide among American Indians. Social Science and Medicine, 56, 1571-1578.

Grubich-Simitis, I. (1981). Extreme traumatization as cumulative trauma: Psychonanalytic investigations of the effects of concentration camp experiences on survivors and their children. Psychoanalytic Study of the Child, 36, 415-450.

Jorgensen, M. \& Taylor,J. (2000). Patterns of Indian enterprise success: A statistical analysis of tribal and individual Indian enterprise performance. Report to the National Congress of American Indians. Cambridge, MA: Harvard Project on American Indian Economic Development, John F. Kennedy School of Government, Harvard University.

Kirmayer, L. (1994). Suicide among Canadian Aboriginal peoples. Transcultural Psychiatry, 31, 3-58.

Krepps, M.B. (1992). Can tribes manage their own resources? The 638 program and American Indian Forestry. In S. Cornell and J. P. Kalt (Eds.), What can tribes do? Strategies and institutions in American Indian economic development. Los Angeles: American Indian Studies Center, UCLA.
MacLaurin, B., Trocmé, N., Fallon, B., Blackstock, C., Pitman, L. \& McCormack, M. (2008). A comparison of First Nations and non-Aboriginal children investigated for maltreatment in Canada in 2003. CECW Information Sheet \#66E. Toronto, ON, Canada: Factor-Inwentash Faculty of Social Work, University of Toronto.

Milloy, J. (1996). A National Crime: The Canadian Government and the Residential School System - 1879 to 1986. Winnipeg: University of Manitoba Press.

Naumetz, T. (2009). Thousands suffered sexual abuse in residential schools. Canoe News. Retrieved 04/02/2009 from http://cnews.canoe.ca/ CNEWS/Politics/2009/01/17/8057196-cp.html.

Piaget, J. (1928). The Child's Conception of the World. London: Routledge and Kegan Paul.

Statistics Canada (2008). Aboriginal Peoples Survey: First Nations Children under six years old living off reserve. Retrieved 02/20/2009 from http://www. statcan.gc.ca/pub/89-637-x/89-637-x2009001-eng.pdf.

Trocmé, N., Fallon, B., MacLaurin, B., Daciuk, J., Felstiner, C. \& Black, T. et al. (2005). Canadian Incidence Study of Reported Child Abuse and Neglect - 2003: Major Findings. Ottawa, ON: Minister of Public Works and Government Services Canada.

United Nations (2006). Consideration of Reports Submitted by States Parties under Articles 16 and 17 of the Covenant. Geneva: United Nations Committee on Economic, Social and Cultural Rights, Economic and Social Council.

van der Kolk, B.A., McFarlane, A.C., \& van der hart, O. (1996). A general approach to treatment of posttraumatic stress disorder. In. B.A. van der Kolk, A.C. McFarlane, and L. Weisaeth (Eds.), Traumatic stress: The effects of overwhelming experience on mind, body and society (pp. 417-440). NY: Guilford Press.

Walls, M. (2007). A Mixed Methods Examination of Indigenous Youth Suicide. Lincoln, Nebraska: The Graduate College at the University of Nebraska.

Walls, M., Johnson, K., Whitbeck, L. \& Hoyt, D. (2006). Mental health and substance abuse services preferences among American Indian people of the northern Midwest. Community Mental Health Journal, 42, 521-535.

Wesley-Esquimaux, C.C. \& Smolewski, M. (2004). Historic Trauma and Aboriginal Healing. Aboriginal Healing Foundation Research Series. Ottawa: Aboriginal Healing Foundation.

Whitbeck, L., Adams, G., Hoyt, D. \& Chen, X. (2004). Conceptualizing and measuring historical trauma among American Indian People. American Journal of Community Psychology, 33, 119-130.

Whitbeck, L., Chen, X., Hoyt, D \& Adams, G. (2004). Discrimination, historical loss and enculturation: Culturally specific risk and resiliency factors for alcohol abuse among American Indians. Journal of Studies on Alcohol, 10, 409-418.

Whitbeck, L., McMorris, B., Hoyt, D, Stubben, J. \& Lafromboise, T. (2002). Perceived discrimination, Traditional practices and depressive symptoms among American Indians in the upper Midwest. Journal of Health and Social Behavior, 43, 400-418. 